NASA Technical Memorandum 106611

AIAA-94-1754

15730

210

\title{
Detection of Delaminations in Composite Beams Using Piezoelectric Sensors
}

Dimitris A. Saravanos

Ohio Aerospace Institute

Brook Park, Ohio

Victor Birman

University of Missouri-Rolla

St. Louis, Missouri

and

is

Dale A. Hopkins

Lewis Research Center

Cleveland, Ohio

Prepared for the

35th Structures, Structural Dynamics, and Materials Conference sponsored by the AIAA, ASME, ASCE, AHS, and ASC Hilton Head, South Carolina, April 18-21, 1994

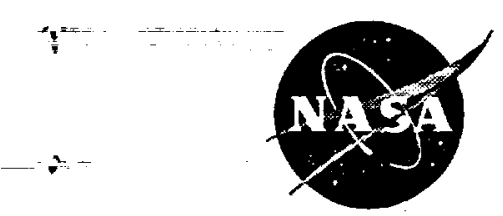

National Aeronautics and Space Administration 


\title{
DETECTION OF DELAMINATIONS IN COMPOSITE BEAMS USING PIEZOELECTRIC SENSORS
}

\author{
Dimitris A. Saravanos* \\ Ohio Aerospace Institute \\ 22800 Cedar Point Road \\ Brook Park, Ohio 44142 \\ Victor Birman ** \\ University of Missour-Rolla \\ St.Louis, Missouri 63121
}

and

Dale A. Hopkins

National Aeronautics and Space Administration

Lewis Research Center

Cleveland, Ohio 44135

\begin{abstract}
SUMMARY
This paper investigates the feasibility of a proposed technique for detecting delaminations using piezoelectric layers or patches embedded or bonded to a composite structure. Variations in the voltage generated in the piezoelectric layers indicates the presence and location of delamination, when the structure is excited either extemally or via piezoelectric actuators. The theoretical foundations of a method for predicting the dynamic response of delaminated composite beams with piezoelectric layers are described. The goveming equations are presented for the case of external vibroacoustic excitation, as well as, for the case of locally induced vibrations by some of the embedded piezoelectric elements. An exact solution is developed within the limits of linear laminate theory. Applications illustrate the feasibility of delamination detection in cantilever beams. The results illustrate that the proposed technique may provide accurate detection of the presence, size and location of a delamination.
\end{abstract}

\section{INTRODUCTION}

Since the advent of composite materials, the development of delamination cracks have represented one of the principal concems to their engineering applications. Delamination cracks may result in catastrophic failure, but also may easily remain undetected. Consequently, numerous theoretical and experimental studies have been conducted to elucidate the effects of delaminations on the static and dynamic response of composite structures. Additional research has addressed the nondestructive detection of delaminations.

The problem of delaminations has received considerable attention as a fracture mechanics problem and the recent papers of Chatterjee (ref. 1), Pindera (ref. 2), Nilsson and Storakers (ref. 3) and Thangjitham and Choi (ref. 4) are mentioned. The vibration and buckling of delaminated composite structures has been also investigated. Simitses (ref. 5) provided a comprehensive bibliography on the subject of buckling of composite plates and beams and a typical formulation of a delaminated beam problem based on a subdivision of the beam into

\footnotetext{
*NASA Resident Research Associate at Lewis Research Center.

${ }^{* *}$ Summer Faculty Fellow at NASA Lewis Research Center.
} 
four regions. Anastasiadis and Simitses (ref. 6) reported also analytical treatments for the case of weak bonding between the delaminated plies. Lee et al. (ref. 7) applied a layer-wise theory to the buckling of a composite beam and considered multiple delaminations through the thickness of the beam using a finite element formulation.

A large number of nondestructive, vibration based, techniques for detection of delaminations have been also developed. A review of vibration methods used for nondestructive evaluations (NDE) of laminated structures was published by Cawley and Adams (ref. 8). Cawley (ref. 9) also reviewed a number of methods suitable for low-frequency NDE. Tracy and Pardoen (ref. 10) presented theoretical and experimental vibration studies on the effects of delamination on the natural frequencies of specialty composite beams. They subdivided the beam in four regions, similar to the approach employed in the buckling studies, used traditional Euler beam theory and neglected extension-flexure coupling effects. Effects of the delamination on the higher natural frequencies were observed, depending on the location and size of delamination. Nagesh Babu and Hanagud (ref. 11) and Paolozzi and Peroni (ref. 12) used finite element models to study the same problem. Their results confirmed the conclusions of Tracy and Pardoen (1989) regarding a reduction in natural frequencies as a result of delamination. Additional finite element solutions have been published by Tenek et al. (ref. 13) (1993). They concluded that the effect of delaminations increases for higher natural frequencies. Shen and Grady (ref. 14) developed equations of motion for a delaminated beam using the $\mathrm{Hu}$-Washizu variational principle and Timoshenko beam theory, and also reported experimental results and correlations. Saravanos (ref. 15) developed an exact analytical procedure for the analysis of delamination effects on the natural frequencies, mode shapes and modal damping of composite beams. The last approach, that represents a version of a layer-wise theory, allows tracing a number of delaminations through the thickness of the laminate.

"High-frequency" nondestructive methods have been also proposed for delamination detection and are briefly reviewed here for the shake of completeness. Velocity measurements of surface waves have been used to nondestructively detect various defects, including delaminations (ref. 16). Buynak et al. (ref. 17) used an ultrasonic technique to produce images of delaminations in graphite-epoxy laminates. Acousto-graphic imaging techniques (ref. 18), and a photothermal method was discussed (ref. 19). Acoustic emission measurements were proposed (refs. 20 and 21 ) to monitor propagation of delaminations. Thermo-acoustic emission was considered (ref. 22) and shearography techniques have been also proposed (ref. 23). Moire interferometry (ref. 24) was also used to detect strain concentrations associated with the presence of delaminations in graphite-epoxy laminates.

A relatively new area of non-destructive delamination monitoring is associated with adaptive or smart structures. These structures may incorporate piezoelectric materials, shape memory alloys, electro-rheological fluids, electrostrictive, and magnetostrictive materials. Nagesh Babu (ref. 11) and Hanagud et al. (ref. 25) recommended the use of piezoelectric sensors to detect delaminations in composite beams. An analytical model for automatic detection and control of delaminations growth using piezoelectric sensors and actuators was discussed (ref. 26), and a four-region model of a delaminated beam based on Timoshenko beam theory was used, while solutions were obtained by the finite element method. Teboub and Hajela (ref. 27) also implemented a four region model of a delaminated beam with piezoelectric sensors for delamination detection under static loads using Kirchhoff type assumptions in each region. An experimental and numerical investigation on applications of piezoelectric sensors to detect delaminations in composite laminates was carried out (ref. 28). Kim et al. (ref. 29) proposed the use of strain gages bonded to the surface or embedded within the laminate.

The present paper investigates the feasibility of a proposed detection technique based on monitoring the spatial voltage distributions across distributed piezoelectric sensors. The proposed technique may provide simple, real-time delamination detection capabilities and requires minimal instrumentation. Hence, it may enhance the health monitoring capacity of composite structures and improve their reliability. Mechanics for composite piezoelectric beams with multiple delaminations and piezoelectric patches bonded to the top and bottom surfaces are developed. An analytical solution is presented, within the limits of the assumptions of linear theory of elastic 
composite beams. The solution is further concentrated on the application of piezoelectric sensors to detect delaminations. Evaluations of the method on cantilever beams illustrate the merits and effectiveness of the proposed technique.

\section{Theoretical Background}

This section presents the theoretical formulation for modelling the dynamic response of delaminated composite beams with embedded piezoelectric sensors and actuators. A number of issues can be addressed in the framework of this formulation including, the detection of delaminations and the control of the dynamic or static response of delaminated beams using some of the piezoelectric elements as sensors and the remaining piezoelectric elements as actuators.

Consider a multilayered beam formed from composite plies and piezoelectric layers, as shown in figure 1(a), with delamination cracks between the composite plies. The delaminations may be at any axial location and may overlap each other. The piezoelectric patches may be bonded to the surfaces or embedded between the composite plies of the beam (fig. 1(a)). Although the theory can handle embedded layers, additional consideration may be required in this case due to local stresses in the vicinity of piezoelectric patches (refs. 30 to 32 ).

For analytical purposes, the beam may be subdivided into four typical segments, A, B, C, and D respectively, as shown in figure 1(b). Type A corresponds to an "ordinary" beam without delaminations and patches. Segments B correspond to the portions of the beam with piezoelectric patches but without delaminations. The segments of the beam with delaminations but without patches are denoted as type C. Finally, the segments D include both delaminations and piezoelectric layers. Note that because of the delamination, the segments $\mathrm{C}$ and $\mathrm{D}$ include two additional subregions separated by a delamination. According to the approach used in this paper, equations of motion are formulated for each subregion within the segments $C$ and $D$ and for each segment (region) A and B independently. The coupling between the admissible solutions is introduced by the continuity conditions for displacements, forces and moments at the boundaries of each region.

The three-dimensional constitutive relations for a piezoceramic material with anisotropic in-plane elastic properties and a macroscopic polar axis aligned with the z-axis are (ref. 33):

$$
\begin{aligned}
& \left\{\begin{array}{l}
\varepsilon_{x} \\
\varepsilon_{y} \\
\varepsilon_{z} \\
\varepsilon_{y z} \\
\varepsilon_{x z} \\
\varepsilon_{x y}
\end{array}\right\}=\left[\begin{array}{rrrrrr}
E & E & E & 0 & 0 & s_{16}^{E} \\
s_{11} & s_{12} & s_{13} & & & E \\
& s_{11} & s_{13} & 0 & 0 & s_{26}^{E} \\
& & s_{33} & 0 & 0 & s_{36}^{E} \\
& & & E & E & 0 \\
& & & s_{44} & s_{45} & 0 \\
& & & & s_{55} & 0 \\
s y m & & & & & E \\
\sigma_{66}
\end{array}\right]\left\{\begin{array}{l} 
\\
\sigma_{x} \\
\sigma_{y} \\
\sigma_{z} \\
\sigma_{y z} \\
\sigma_{x z} \\
\sigma_{x y}
\end{array}\right\}+\left[\begin{array}{c}
d_{31} E_{z} \\
d_{31} E_{z} \\
d_{33} E_{z} \\
d_{15} E_{y} \\
d_{15} E_{x} \\
0
\end{array}\right] \\
& D_{x}=d_{15} \sigma_{x z}+e_{11}^{T} E_{x}
\end{aligned}
$$




$$
\begin{gathered}
D_{y}=d_{15} \sigma_{y z}+\imath_{11}^{T} E_{y} \\
D_{z}=d_{31}\left(\sigma_{x}+\sigma_{y}\right)+d_{33} \sigma_{z}+2{ }_{33}^{T} E_{z}
\end{gathered}
$$

where $\varepsilon$ and $\sigma$ indicate engineering strains and stresses respectively. The matrices $\mathrm{s}_{\mathrm{mn}}^{\mathrm{E}}, \mathrm{d}_{\mathrm{mn}}$ and $\tau_{m m}^{T}$ are the elastic compliances, piezoelectric constants, and dielectric permittivity respectively. Superscripts $\mathrm{E}$ and $\mathrm{T}$ indicate that the corresponding properties should be measured in constant electric field and constant stress conditions respectively. $E_{i}$ and $D_{i}$ are the components of the electric field and electric displacements. In the case of a thin beam it may be assumed that $\sigma_{\mathrm{y}}=\sigma_{\mathrm{z}}=\sigma_{\mathrm{ij}}=0$, which simplifies the constitutive equations as follows,

$$
\begin{aligned}
& \sigma_{x}=c_{11}^{*}\left(\varepsilon_{x}-d_{31} E_{z}\right) \\
& D_{z}=d_{31} \sigma_{x}+\varepsilon{ }_{33}^{T} E_{z}
\end{aligned}
$$

where $c^{*}{ }_{11}=1 / S_{11}$ is the equivalent axial modulus of the material.

It is assumed that the problem is geometrically linear, moreover, the transverse shear deformations and rotary inertia are considered negligible. It is further assumed that $u^{k}=u^{k}(x)$ and $w^{k}=w^{k}(x)$ are the axial and through-the-thickness displacements at the mid-plane of the $k$-th region (or subregion), while the transverse displacement is assumed negligible $\left(\mathrm{v}^{\mathrm{k}}(\mathrm{x})=0\right)$. Then the strain-displacement relationship for thin sections is:

$$
\varepsilon_{x}=u_{, x}^{k}-z_{k} w_{, x x}^{k}
$$

where $z_{k}$ is the distance from the mid-plane axis of each region.

Integration of the previous equation through the thickness of the beam and combination with equations (2) yields the stress and moment resultants $\mathrm{N}_{\mathrm{x}}{ }^{\mathrm{k}}$ and $\mathrm{M}_{\mathrm{x}}{ }^{\mathrm{k}}$ respectively, in the $\mathrm{k}$-th region of the beam,

$$
\left\{\begin{array}{c}
N_{x}^{k} \\
M_{x}^{k}
\end{array}\right\}=\left[\begin{array}{ll}
A_{k} & B_{k} \\
B_{k} & D_{k}
\end{array}\right]\left\{\begin{array}{c}
u_{, x}^{k} \\
-w_{, x x}^{k}
\end{array}\right\}=\left\{\begin{array}{c}
F_{k} \\
G_{k}
\end{array}\right\}
$$

where A, B, and D are the extensional, coupling and bending stiffness of the beam,

$$
\left\{A_{k}, B_{k}, D_{k}\right\}=\sum_{m=1}^{n_{l k}} \int_{z_{m}}^{z_{m^{+}} 1} c_{11}^{*}\left\{1, z, z^{2}\right\} d z
$$

and $F, G$ are the piezoelectric force and moment resultants respectively, 


$$
\left\{F_{k}, G_{k}\right\}=\sum_{m=1}^{n_{l k}} \int_{z_{m}}^{z_{m+1}} c_{11}^{*} d_{31}\{1, z\} E_{z} d z
$$

$\mathrm{n}_{\mathrm{lk}}$ indicates the number of plies across the k-th region (or subregion) of the beam, In segment A (see fig. 1(b)), $n_{1 k}$ is the number of composite plies through the depth $h$ of the beam; in segment(s) $B n_{1 k}$ must be modified to incorporate the piezoelectric patches; in segments $C$ and $D$, the limits of integration must be chosen to include the corresponding delaminated sublaminates.

The equations of motion in the $\mathrm{k}$-th region of the beam, assuming that the axial inertia effects are negligible, are:

$$
\begin{aligned}
& N_{x, x}^{k}=0 \\
& M_{x, x x}^{k}=\rho_{k} \ddot{w}^{k}-q(x, t)
\end{aligned}
$$

where $q(x, t)$ is an external load, and

$$
\rho_{k}=\int_{z_{k}}^{z_{k+1}} \rho(z) d z
$$

where $\rho$ is the linear density of the beam.

Substitution of equations (4) into equations (7) yields the equation of motion for the kth region:

$$
\begin{gathered}
A_{k} u_{, x x}^{k}-B_{k} w_{, x x x}^{k}-F_{k}\left(E_{z, x}, t\right)=0 \\
B_{k} u_{, x x x}^{k}-D_{k} w_{, x x x x}^{k}-G_{k}\left(E_{z, x x}, t\right)-\rho_{k} \ddot{w}^{k}=q(x, t)
\end{gathered}
$$

Equations (9) and (10) can be used to analyze the motion of the beam when it is excited by external loads (sensory beam), as well as, when it is excited by some of the piezoelectric layers (sensory/active beam). In the sensory case, an external load $q(x, t)$ is present, while the imposed electric field $E_{z}$ in the piezoelectric layers is zero. In a sensory/active beam, electric fields $E_{z}$ may be imposed in some of the piezoelectric layers to induce additional vibrations, while external mechanical loads $q(x, t)$ may be present.

The solution must satisfy the boundary conditions at the supports. For example, the free-end conditions are $N_{x}=M_{x}=V_{x}=0$, where $V_{x}$ is the shear force, and the clamped conditions are $u=w=w_{, x}=0$. Additional kinematic continuity conditions between the $k$-th and $(k+1)$-th regions at $x=x_{r}$ are imposed:

$$
\begin{gathered}
\left.\left.u^{k} \mid x_{r}\right)=u^{k+1}\left|x_{r}\right|, \quad w^{k}\left|x_{r}\right|=w^{k+1} \mid x_{r}\right), \\
\left.\left.w_{, x}^{k} \mid x_{r}\right)=w_{, x}^{k+1} \mid x_{r}\right)
\end{gathered}
$$


Continuity in the balance of axial forces, bending moments and shear forces is also required

$$
\begin{aligned}
\sum_{k} N_{x}^{k}\left(x_{r}^{-}\right) & =\sum_{j} N_{x}^{j}\left(x_{r}^{+}\right) \\
\sum_{k}\left[M_{x}^{k}\left(x_{r}^{-}\right)+N_{x}^{k}\left(x_{r}^{-}\right) \bar{z}_{k}\right] & =\sum_{j}\left[M_{x}^{j}\left(x_{r}^{+}\right)+N_{x}^{j}\left(x_{r}^{+}\right) \bar{z}_{j}\right] \\
\sum_{k} V_{x}^{k}\left(x_{r}^{-}\right) & =\sum_{j} V_{x}^{j}\left(x_{r}^{+}\right)
\end{aligned}
$$

where the indices $k$ and $j$ identify the number of subregions to the left $\left(x_{r}^{-}\right)$and to the right $\left(x_{r}^{+}\right)$, respectively, of a cross-section at $\mathrm{x}=\mathrm{x}_{\mathrm{r}}$. The coordinates $\bar{z}_{k}$ reflect the distance of the elastic axes of the corresponding subregions to the mid-plane of the beam. The shear forces in equation (12.3) are given by:

$$
V_{x}^{r}=M_{x, x}^{r}+N_{x}^{r} w_{x}^{r}
$$

where ( $r=k$ or $\mathrm{j}$ ). In the absence of external axial forces, the last term in the right side of equation (13) may be neglected and equation (12.3) becomes:

$$
\left.\sum_{k} M_{x, x}^{k} \mid x_{n}\right)=\sum_{j} M_{x, x}^{j}\left(x_{n}\right)
$$

The governing equations (9-10) together with the boundary conditions and continuity conditions (12) formulated in this section represent the necessary analytical relations for the solution of problems of active and passive control of composite beams with delaminations. In the next section applications of the theory for the detection of delaminations are presented.

\section{Detection of Delaminations}

This section further extends the method for the detection of delaminations under dynamic excitation. In the proposed scheme, distributed piezoelectric sensors are used to detect the presence, size and location of delaminations, when the beam is excited either passively or actively by some of the piezoelectric layers. In both cases, the voltages generated across the piezoelectric sensors in an intact (pristine) beam, are different than those in the delaminated counterpart.

Consider the more general case where the beam is excited by either an external harmonic load $q(x) e^{i \omega t}$ or an applied harmonic electric field $\bar{E}_{z}(x) e^{i \omega t}$ at some of the piezoelectric layers (actuators). It is customary to neglect the effect of a self-generated voltage on the motion (ref. 34), however, techniques for incorporating these effects have been reported by Heyliger and Saravanos (ref. 32) and may be included in future work. The displacements are assumed to have the form

$$
\left\{u^{k}, w^{k}\right\}=\left\{U^{k}, W^{k}\right\} e^{s x} e^{i \omega t}
$$

and the equations of motion (9-10) are reduced to: 


$$
\begin{gathered}
A_{k} U_{x}^{k}-B_{k} W_{, x x}^{k}=\bar{N}_{k} \\
B_{k} U_{, x x x}^{k}-D_{k} W_{, x x x x}^{k}=-\rho_{k} \omega^{2} W^{k}-q_{k}(x)
\end{gathered}
$$

where $\bar{N}_{k}$ is a constant and $\mathrm{q}_{\mathrm{k}}$ is the amplitude of the external load acting on the region.

The solution of equations (16) is:

$$
\begin{gathered}
W^{k}=C_{1}^{k} \sin s_{k} x+C_{2}^{k} \cos s_{k} x+C_{3}^{k} e^{s_{k} x}+C_{4}^{k} e^{-s_{k} x}+Q_{k}+R_{k} \\
U^{k}=C_{5}{ }^{k}+\frac{\bar{N}_{k}}{A_{k}} x+\frac{B_{k} s_{k}}{A_{k}}\left(C_{1}^{k} \cos s_{k} x-C_{2}^{k} \sin s_{k} x+C_{3}^{k} e^{s_{k} x} \cdot C_{4}^{k} e^{-s_{k}{ }^{x}}\right)+P_{k}
\end{gathered}
$$

where $C_{1}{ }^{k}$ through $C_{5}{ }^{k}$ are coefficients of integration and

$$
\begin{gathered}
s_{k}=\frac{\rho_{k} \omega^{2}}{D_{k}-B_{k}^{2} / A_{k}} \\
P_{k}=\frac{1}{A_{k}} \int F_{k}\left(\bar{E}_{z}\right) d z, \quad R_{k}=G_{k}\left(\bar{E}_{z, x x}\right) / \rho_{k} \omega^{2} \\
Q_{k}=-q_{k} / \rho_{k} \omega^{2}
\end{gathered}
$$

Note that integration of the system of equations (16) results in 5 constants of integration for each beam region including the constant $\bar{N}_{k}$. The number of boundary and continuity conditions is proved to be always equal to the number of coefficients of integration. Hence, a linear system of algebraic equations results by substituting equation (17) into the boundary and continuity conditions, of the form

$$
\left[a_{i j}\right]\left|C_{j}\right\rangle=\left\langle f_{i}\right|
$$

where $\left[\alpha_{i j}\right]$ is a square matrix, $\left[C_{i}\right]$ is the vector of unknown coefficients in equations $(17)$, and $\left[f_{i}\right]$ is a vector of loading terms. The elements of the matrix [a] are independent to the method of excitation (passive or active). Once the constants of integration are determined, the displacements, strains and stresses can be evaluated.

The electric potential difference (voltage) $\delta \phi$ generated across the sensory piezoelectric layers or patches can be calculated as

$$
\delta \phi(t)=-\int_{h_{p}} E_{z}(t) d z
$$

where $h_{p}$ is a thickness of the corresponding piezoelectric layer. The positive direction of the electric field component coincides with the one of the z-axis. Combining equations (2), the electric field can be obtained from

$$
E_{z}=\frac{1}{c_{11}^{\prime} d_{31}^{2}-\iota_{33}^{T}}\left|c_{11}^{\prime} d_{31} \varepsilon_{x}-D_{z}\right|
$$

In a sensory piezoelectric layer the electric circuit remains practically open, hence, the total charge $D_{z}$ over the length $\mathrm{l}_{\mathrm{p}}$ of the electrodes remains constant and can be assumed equal to zero,

$$
\int_{l_{p}} D_{z} d x=0
$$

Combining equations (21) and (22), and considering that the terminals impose a constant electric potential condition along its length $l_{p}$, the voltage output across the electrodes of a sensor can be obtained as: 


$$
\delta \phi(t)=-\frac{c_{11} d_{31}}{\left|c_{11} d_{31}^{2}-e_{33}^{T}\right| l_{p}} \int_{l_{p}} \int_{h_{p}} \varepsilon_{x}(t) d z d x
$$

Passive Excitation.-In the case of external mechanical excitation, the terms in equation (18.2) vanish, hence, the right hand side term $\left\{f_{i}\right\}$ in equation (19) contains only terms related to the mechanical load.

Piezoelectric Excitation.- In addition to external mechanical excitation, voltage may be applied across some of the piezoelectric layers/patches to actively excite the beam. This inclusion of piezoelectric excitation requires only modification of the loading vector $\left\{f_{i}\right\}$ in equation (19). If the motion of the beam is excited by a uniform sinusoidal voltage applied to a continuous actuator-layer, the solution of the equations of motion is given by equations (17) (where $F_{k}$ may or may not be zero) and $U^{k}$ is complemented by the following additional term:

$$
P_{k}=\frac{\bar{E}_{z} x^{z_{k+1}}}{A_{k}} \int_{z_{k}}^{c_{11}^{k}} c_{31}^{k} d z
$$

\section{APPLICATIONS AND DISCUSSION}

\section{Materials and Assumptions}

Evaluations of the previously described model were performed for sensory composite beams. The composite plies were T300/934 graphite/epoxy of 0.60 fiber volume ratio. The piezoceramic PZT5A was selected as the material for the piezoelectric layer(s) with properties provided by the manufacturer (ref. 35). This material is recommended for sensor applications by the manufacturer. The material properties are shown in Table 1.

Eight ply symmetrically laminated beams with a single delamination and 2 piezoceramic layers, each bonded to the top and bottom surface of the composite beam, were considered in the numerical examples. Unless otherwise stated, a cross-ply layup $[\mathrm{p} / 0 / 90 / 0 / 90]_{\mathrm{s}}$ was mostly considered, where " $\mathrm{p}$ " denotes a piezoceramic layer. Laminations of the type $[\mathrm{p} / 0 / 90 / 45 /-45]_{\mathrm{s}}$ and $[\mathrm{p} / 0 / 45 /-45 / 0]_{\mathrm{s}}$ were also investigated. The length of the beam was equal to 5 in, its width was 1 in, and the thickness of each layer was 0.01 in. Results are presented for a cantilever beam clamped at the left end.

The beams were assumed to be excited by a uniformly distributed load of $1 \mathrm{lb} /$ in amplitude applied on the upper surface of the beam at a frequency of $80 \mathrm{~Hz}$ which is lower than the fundamental frequency. This low frequency was selected to avoid excitation of the higher modes that could complicate the interpretation of the results. The terminals were assumed closely spaced having infinitesimal length, such that they yield continuous voltage readings along the free surfaces.

\section{Effect on Dynamic Deflections}

The first phase of the analysis evaluates the effect of delamination on the transverse dynamic deflections of the sensory beam. In the case of a cantilever beam these effects are quite significant. As follows from figure 2 , increases in the delamination length resulted in significant increases in the amplitude of vibration. This is associated with the reduction of stiffness in the delaminated beam. The predicted influence of local vibration modes in the delaminated regions on the global mode shape appears negligible both in the present and in the following examples. 
The location of a delamination through the depth of the cantilever beam had a minimal effect on the motion (see fig. 3). The two cases compared in figure 3 include: a delamination located at the mid-plane of the beam (mid-plane case); and a delamination located near the upper surface (off-plane case) such that [p/0/90/0/90/90/0/190/0/p], where // indicates the presence of the crack. Considering various axial locations of delaminations in figure 4 , the axial location of a delamination has a relatively larger effect. As expected, the displacement amplitudes increase as the delamination approaches the clamped end of the beam, indicating that such delaminations result in more pronounced reductions of the stiffness.

\section{Sensory Response}

The following paragraphs present the predicted voltage output across the piezoelectric sensors. The outputs from the cantilever beam with centrally located delaminations of various lengths are shown in figures 5 to 7 . In these figures, as well as in the following figures, the two curves represent the amplitudes of the resultant AC voltage across the lower and upper piezoelectric layer (referred to as "lower" and "upper" layers) respectively. Apparently the presence of the delamination can be detected either from the resultant discontinuities in the voltage output along each surface, or from the resultant difference in the voltage amplitudes between the sensors in the upper and lower surfaces (see figs. 5 to 7 ). More importantly the size and axial location of the delamination are sharply outlined. In practice, such an accurate detection of a delamination will be limited by the finite number and size of sensors/electrodes, however, the spacing of the sensors is a design problem which should be solved in conjunction the allowable minimum length of a detectable delamination.

The predicted effect of an axially shifted delamination on the voltage outputs of a cantilever beam is shown in figures 8 to 9 . In both cases, voltage readings clearly indicate the presence, axial location and size of the delamination. The resultant voltage change is lower when the delamination is near the free-end, as opposed to a delamination near the root. This happens because the axial strain in the piezoelectric layers also decreases towards the free end.

The voltage output of the piezoelectric sensors is also sensitive to the through-the-thickness location of delamination (see figs. 10 and 11). Figure 10 corresponds to a delamination located near the top surface of the beam, while figure 11 to a delamination near the bottom surface. The differences between the figures (compare also to figure 5 where the delamination lies on the mid-plane) indicates that the proposed technique may also reveal the lateral location of a delamination, in addition to detecting the presence and axial location.

The laminate layup did not affect significantly the conclusions obtained in the previous examples. This was verified for a central delamination in cantilever beams with laminations $[\mathrm{p} / 0 / 90 / 45 /-45]_{\mathrm{s}}$ and $[\mathrm{p} / 0 / 45 /-45 / 0]_{\mathrm{s}}$ respectively. Figure 12 compares the predicted voltage output of a $[\mathrm{p} / 0 / 90 / 0 / 90]_{\mathrm{s}}$ and a $[\mathrm{p} / 0 / 45 /-45 / 0]_{\mathrm{s}}$ cantilever beam with 20 percent central delaminations at their mid-plane. Although there are some differences in the voltage output, the detection of delamination is not affected.

The proposed technique is not also affected by the supporting conditions of the beam. This is clearly demonstrated in figure 13 , where the sensory response of a $[\mathrm{p} / 0 / 90 / 0 / 90]_{\mathrm{s}}$ simply supported beam is shown. The beam has a 20 percent central delamination at the mid-plane. As was expected the different supporting conditions result in different voltage distributions, yet, the presence, size and axial location of delamination may be detected by the discontinuities in the voltage distributions along each surface. Additional case studies were conducted, similar to the ones presented for the sensory cantilever beam case, and indicated that the simplysupporting conditions din not affect the effectiveness and capability of the proposed technique to detect the presence, size, and axial/lateral location of a delamination. 


\section{SUMMARY AND CONCLUSIONS}

A technique for detecting delaminations in vibrating composite beams was proposed, and the associated mechanics were developed. The proposed scheme is based on monitoring the changes in the voltage output signature of distributed piezoelectric sensors bonded to or embedded into the vibrating structure. The vibrations may be induced either externally (mechanically or acoustically) or by using piezoelectric actuators.

The method was applied to detect delaminations in composite beams. Based on the obtained results, the following conclusions are summarized. The predicted response of the piezoelectric sensors was very sensitive to the presence of a delamination. It was observed that in the case of continuous piezoelectric layers with infinitesimally spaced terminals bonded to the upper and lower surfaces, abrupt axial discontinuities in the AC voltage output across the sensors indicate clearly the crack tips. Moreover, resultant voltage differences between the sensors in upper and lower surfaces may be used to directly detect the presence of delamination. Hence, the proposed concept can detect the presence of a delamination and predict its size and location both axially and through-the-thickness of a composite structure. The effectiveness of the detection was not affected by the type of boundary conditions. This was illustrated by analyzing simply supported and cantilever beams.

In closing, the reported research has demonstrated the feasibility of the proposed technique. The method described herein can be successfully extended to detect delaminations in composite plates and shells. Future work will address the effectiveness of the method when limited numbers of sensors are implemented, and the experimental verification of the proposed technique.

\section{ACKNOWLEDGMENT}

This research was conducted during the ASEE summer faculty fellowship of Dr. V. Birman to the NASA Lewis Research Center.

\section{REFERENCES}

1. Chatterjee, S.N., 1987: "Three and Two-Dimensional Stress Fields Near Delaminations in Laminated Composite Plates," International Journal of Solids and Structures, Vol. 23, pp. 1535-1549.

2. Pindera, M.-J., 1991: "Local/Global Stiffness Matrix Formulation for Composite Materials and Structures," Composites Engineering, Vol. 1, pp. 69-83.

3. Nilsson, K.-F. and Storakers, B., 1992: "On Interface Crack Growth in Composite Plates," Journal of Applied Mechanics, Vol. 59, pp. 530-538.

4. Thangiitham, S. and Choi, H.J., 1993: "Interlaminar Crack Problems of a Laminated Anisotropic Medium," International Journal of Solids and Structures, Vol. 30, pp. 963-980.

5. Simitses, G.J., 1993: "Delamination Buckling of Flat Laminates," Buckling and Postbuckling of Composite Plates, Eds., Turvey, G. J. and Marshall, I., Elsevier, In press.

6. Anastasiadis, J.S. and Simitses, G.J., 1991: "Spring Simulated Delamination of Axially-Loaded Flat Laminates," Composite Structures, Vol. 17, pp. 67-85. 
7. Lee, J., Gurdal, Z. and Griffin, O.H., Jr., 1992: "A Layer-Wise Approach for the Bifurcation Problem in Laminated Composites with Delaminations," AIAA Paper 92-2224-CP.

8. Cawley, P. and Adams, R.D., 1987: "Vibration Techniques (of NDT)," Nondestructive Testing of FibreReinforced Plastics Composites, Vol. 1, Ed., Summerscales, J., Elsevier, London, pp. 151-200.

9. Cawley, P., 1990: "Low Frequency NDT Techniques for the Detection of Disbonds and Delaminations," British Journal of Nondestructive Testing, Vol. 32, pp. 454-461.

10. Tracy, J.J. and Pardoen, G.C., 1989: "Effect of Delamination on the Natural Frequencies of Composite Laminates," Joumal of Composite Materials, Vol. 23, pp. 1200-1215.

11. Nagesh Babu, G.L. and Hanagud, S., 1990: "Delaminations in Smart Composite Structures: A Parametric Study on Vibrations," AIAA Paper 90-1173-CP, 31st AIAA/ASME/ASCE/AHS/ASC SDM Conference, Part 4, pp. 2417-2426.

12. Paolozzi, A. and Peroni, I., 1990: "Detection of Debonding Damage in a Composite Plate Through Natural Frequency Variations," Journal of Reinforced Plastics and Composites, Vol. 9, pp. 369-389.

13. Tenek, L.H., Henneke, E.G. II, and Gunzburger, M.D., 1993: "Vibration of Delaminated Composite Plates and Some Applications to Non-Destructive Testing," Composite Structures, Vol. 23, 253-262.

14. Shen, M.H.H. and Grady, J.E., 1992: "Free Vibrations of Delaminated Beams," NASA TM 105582.

15. Saravanos, D.A., 1993: "Mechanics for the Effects of Delaminations on the Dynamic Characteristics of Composite Laminates," Dynamic Characteristics of Advanced Materials, Eds. P.K. Raju and R.F. Gibson. ASME Winter Annual Meeting, NCA-Vol 16/AMD-Vol. 172, ASME, pp. 11-21.

16. Rose, J.L., Pilarski, A. and Huang, Y., 1990: "Surface Wave Utility in Composite Material Characterization," Research in Nondestructive Evaluation, Vol. 1, pp. 247-265.

17. Buynak, C.F., Moran, T.J. and Martin, R.W., 1989: Delamination and Crack Imaging in Graphite-Epoxy Composites," Materials Evaluation, Vol. 47, pp. 438-441.

18. Sandhu, J.S., 1988: “Acoustography: A New Imaging Technique and its Applications to Nondestructive Evaluation," Materials Evaluation, Vol. 46, pp. 608-613.

19. Balageas, D.L., Deom, A.A. and Boscher, D.M., 1987: "Characterization and Nondestructive Testing of Carbon-Epoxy Composites by a Pulsed Photothermal Method," Materials Evaluation, Vol. 45, pp. 461-465.

20. Garg, A. and Ishai, O., 1985: "Characterization of Damage Initiation and Propagation in Graphite/Epoxy Laminates by Acoustic Emission," Engineering Fracture Mechanics, Vol. 22, pp. 595-608.

21. Kexing, L., Davis, A., Ohn, M.M., Byung, P., Measures, R.M., 1992: "Embedded Optical Fiber Sensors for Damage Detection and Cure Monitoring," Proceedings of the ADPAAIAAVASME/SPIE Conference on Active Materials and Adaptive Structures, IOP Publishing, Bristol, pp. 395-398.

22. Sato, N., Kurauchi, T. and Kamigaito, O., 1986: "Thermo-Acoustic Emission from Damaged Composite," Proceedings, 31st International SAMPE Symposium: Materials Sciences for the Future, Eds., Bauer, J. L. and Dunaetz, R., Soc. Adv. Mater. \& Process Engineering, Covina, CA, pp. 342-351. 
23. Hung, Y.Y., 1989: "Shearography: A Novel and Practical Approach for Nondestructive Testing," Nondestructive Evaluation, Vol. 8, No. 1 pp. 55-67.

24. Wood, J.D., 1985: "Detection of Delamination Onset in a Composite Laminate using Moire Interferometry," Joumal of Composites Technology and Research, Vol. 7, pp. 121-128.

25. Hanagud, S., Nagesh Babu, G.L. and Won, C.C., 1990: "Delaminations in Smart Composite Structures," Proceedings, The 1990 SEM Spring Conference on Experimental Mechanics, Bethel, CT, Society for Experimental Mechanics, Inc., pp. 776-781.

26. Hanagud, S., Nagesh Babu, G.L., Roglin, R.L. and Savanur, S.G., 1992: "Active Control of Delaminations in Composite Structures," Proceedings, 33rd AIAA/ASME/ASCE/AHS/ASC SDM Conference, Dallas, TX, pp. 1819-1829 (AIAA Paper 92-2387-CP).

27. Teboub, Y. and Hajela, P., 1992: "A Neural Network Based Damage Analysis of Smart Composite Beams," AIAA Paper 92-4685, Fourth AIAA/USAF/NASA/OAI Symposium on Multidisciplinary Analysis and Optimization, September 21-23, 1992, Cleveland, OH.

28. Keilers, C.H., Jr., and Chang, F-K., 1993: "Damage Detection and Diagnosis of Composites Using Built-In Piezoceramics," Proceedings of the 1993, North American Conference on Smart Structures and Materials, Albuquerque, NM, In press.

29. Kim, K-S, Segall, A. and Springer, G.S., 1993: "The Use of Strain Measurements for Detecting Delaminations in Composite Laminates," Composite Structures, Vol. 23, pp. 75-84.

30. Joshi, S.P. and Chan, W.S., 1992: "Damage-Survivable and Damage-Tolerant Laminated Composites with Optimally Placed Piezoelectric Layers," Final Report No.1, U.S. Army Research Office, Grant No. DAAL03-89-G-0090, University of Texas at Arlington, Arlington, Texas.

31. Warkentin, D.J., Crawley, E.F. and Senturia, S.D., 1992: "The Feasibility of Embedded Electronics for Intelligent Structures," Journal for Intelligent Material Systems and Structures, Vol. 3, pp. 462-482.

32. Heyliger P.R. and Saravanos D.A., 1993: "On Discrete-Layer Mechanics for Health Monitoring Application In Smart Composite Structures," Adaptive Structures and Material Systems, eds. G.P. Carman and E. Garcia, ASME Winter Annual Meeting, AD-Vol. 35, ASME, pp. 303-312.

33. Smith, W.A., 1992: "The Key Design Principle for Piezoelectric Ceramic/Polymer Composites," Recent Advances in Adaptive and Sensory Materials and their Applications, Eds., Rogers, C. A. and Rogers R. C., Technomic, Lancaster, pp. 825-838.

34. Tzou, H.S., 1993: "Piezoelectric Shells," Kluwer Academic Publishers, Dordrecht.

35. "Guide to Modern Piezoelectric Ceramics," 1993, Morgan Matroc, Inc., Electro Ceramics Division, Bedford, Ohio 44145. 


\section{APPENDIX}

\section{Elements of Matrix $\left[a_{i j}\right]$ and Vector $\left\{f_{j}\right\}$ for a Composite Beam with Single Delamination.}

The right end of the beam is free to move in the axial direction while the left end is completely restrained. Therefore, it can be shown that $\bar{N}_{1}=\bar{N}_{4}=0$ and $\bar{N}_{2}=-\bar{N}_{3}$. The system of equations (19) is reduced to 21 equations. The vector $\left\{C_{j}\right\}$ includes the following elements:

$$
\begin{aligned}
& \left\{C_{j}\right\}^{T}=\left\{C_{1}^{1} C_{2}^{1} C_{3}^{1} C_{4}^{1} C_{5}^{1} C_{1}^{2} C_{2}^{2} C_{3}^{2} C_{4}^{2} C_{5}^{2}\right. \\
& \left.C_{1}^{3} C_{2}^{3} C_{3}^{3} C_{4}^{3} C_{5}^{3} C_{1}^{4} C_{2}^{4} C_{3}^{4} C_{4}^{4} C_{5}^{4} \bar{N}_{2}\right\}
\end{aligned}
$$

\section{Simply supported beam subjected to a mechanical load}

Matrix $\left[a_{i j}\right]$ : The elements $a_{i j}$ are written in the form $a(i, j)$. Elements that are not listed are equal to zero.

1. $i=1$

$$
a(1,2)=a(1,3)=a(1,4)=1
$$

2. $i=2$

$$
a(2,2)=-a(2,3)=-a(2,4)=\bar{D}_{1}
$$

3. $i=3$

$$
a(3,1)=a(3,3)=-a(3,4)=\bar{B}_{1} \quad a(3,5)=1
$$

4. $i=4$

$$
a(4,16)=t_{4} \quad a(4,17)=c_{4} \quad a(4,18)=e_{4} \quad a(4,19)=e_{40}
$$

5. $i=5$

$$
a(5,16)=D_{4} t_{4} \quad a(5,17)=D_{4} c_{4} \quad a(5,18)=-D_{4} e_{4} \quad a(5,19)=-D_{4} e_{40}
$$

6. $i=6$ $a(6,1)=-B_{12} c_{1}$ $a(6,5)=-1$ $a(6,9)=-\bar{B}_{2} e_{20}$

7. $i=7$

$$
\begin{array}{llll}
a(7,1)=-B_{13} c_{1} & a(7,2)=B_{13} t_{1} & a(7,3)=-B_{13} e_{1} & a(7,4)=B_{13} e_{10} \\
a(7,5)=-1 & a(7,11)=-\bar{B}_{3} c_{3} & a(7,12)=-\bar{B}_{3} t_{3} & a(7,13)=\bar{B}_{3} e_{3} \\
a(7,14)=\bar{B}_{3} e_{30} & a(7,15)=1 & a(7,21)=-\frac{l_{1}}{A_{3}}
\end{array}
$$

8. $i=8$

$$
\begin{array}{llll}
a(8,1)=t_{1} & a(8,2)=c_{1} & a(8,3)=e_{1} & a(8,4)=e_{10} \\
a(8,6)=-t_{2} & a(8,7)=-c_{2} & a(8,8)=-e_{2} & a(8,9)=-e_{20}
\end{array}
$$


9. $i=9$

$\begin{array}{llll}a(9,1)=t_{1} & a(9,2)=c_{1} & a(9,3)=e_{1} & a(9,4)=e_{10} \\ a(9,11)=-t_{3} & a(9,12)=-c_{3} & a(9,13)=-e_{3} & a(9,14)=-e_{30}\end{array}$

10. $i=10$

$$
\begin{array}{llll}
a(10,1)=s_{1} c_{1} & a(10,2)=-s_{1} t_{1} & a(10,3)=s_{1} e_{1} & a(10,4)=-s_{1} e_{10} \\
a(10,6)=-s_{2} c_{2} & a(10,7)=s_{2} t_{2} & a(10,8)=-s_{2} e_{2} & a(10,9)=s_{2} e_{20}
\end{array}
$$

11. $i=11$

$$
\begin{array}{llll}
a(11,1)=s_{1} c_{1} & a(11,2)=-s_{1} t_{1} & a(11,3)=s_{1} e_{1} & a(11,4)=-s_{1} e_{10} \\
a(11,11)=-s_{3} c_{3} & a(11,12)=s_{3} t_{3} & a(11,13)=-s_{3} e_{3} & a(11,14)=s_{3} e_{30}
\end{array}
$$

12. $i=12$

$$
\begin{array}{llll}
a(12,6)=\bar{B}_{2} c_{5} & a(12,7)=-\bar{B}_{2} t_{5} & a(12,8)=\bar{B}_{2} e_{5} & a(12,9)=-\bar{B}_{2} e_{50} \\
a(12,10)=1 & a(12,16)=-B_{12} c_{6} & a(12,17)=B_{12} t_{6} & a(12,18)=-B_{12} e_{6} \\
a(12,19)=B_{12} e_{60} & a(12,20)=-1 & a(12,21)=\frac{I_{2}}{A_{2}}
\end{array}
$$

13. $i=13$

$$
\begin{array}{llll}
a(13,11)=\bar{B}_{3} c_{7} & a(13,12)=-\bar{B}_{3} t_{7} & a(13,13)=\bar{B}_{3} e_{7} & a(13,14)=-\bar{B}_{3} e_{70} \\
a(13,15)=1 & a(13,16)=-B_{13} c_{6} & a(13,17)=B_{13} t_{6} & a(13,18)=-B_{13} e_{6} \\
a(13,19)=B_{13} e_{60} & a(13,20)=-1 & a(13,21)=-\frac{I_{2}}{A_{3}} &
\end{array}
$$

14. $i=14$

$$
\begin{array}{llll}
a(14,6)=t_{5} & a(14,7)=c_{5} & a(14,8)=e_{5} & a\left(14,9=e_{50}\right. \\
a(14,16)=-t_{6} & a(14,17)=-c_{6} & a(14,18)=-e_{6} & a(14,19)=-e_{60}
\end{array}
$$

15. $i=15$

$$
\begin{array}{llll}
a(15,11)=t_{7} & a(15,12)=c_{7} & a(15,13)=e_{7} & a(15,14)=e_{70} \\
a(15,16)=-t_{6} & a(15,17)=-c_{6} & a(15,18)=-e_{6} & a(15,19)=-e_{60}
\end{array}
$$

16. $i=16$

$$
\begin{array}{llll}
a(16,6)=-s_{2} c_{5} & a(16,7)=s_{2} t_{5} & a(16,8)=-s_{2} e_{5} & a(16,9)=s_{2} e_{50} \\
a(16,16)=s_{1} c_{6} & a(16,17)=-s_{1} t_{6} & a(16,18)=s_{1} e_{6} & a(16,19)=-s_{1} e_{60} \\
i=17 & & & \\
a(17,11)=-s_{3} c_{7} & a(17,12)=s_{3} t_{7} & a(17,13)=-s_{3} e_{7} & a(17,14)=s_{3} e_{70} \\
a(17,16)=s_{1} c_{6} & a(17,17)=-s_{1} t_{6} & a(17,18)=s_{1} e_{6} & a(17,19)=-s_{1} e_{60}
\end{array}
$$

17. $i=17$

18. $i=18$

$$
\begin{array}{lrrr}
a(18,1)=-\bar{D}_{1} s_{1}^{3} c_{1} & a(18,2)=\bar{D}_{1} s_{1}^{3} t_{1} & a(18,3)=\bar{D}_{1} s_{1}^{3} e_{1} & a(18,4)=-\bar{D}_{1} s_{1}^{3} e_{10} \\
a(18,6)=\bar{D}_{2} s_{2}^{3} c_{2} & a(18,7)=-\bar{D}_{2} s_{2}{ }^{3} t_{2} & a(18,8)=-\bar{D}_{2} s_{2}^{3} e_{2} & a(18,9)=\bar{D}_{2} s_{2}{ }^{3} e_{20} \\
a(18,11)=\bar{D}_{3} s_{3}{ }^{3} c_{3} & a(18,12)=-\bar{D}_{3} s_{3}{ }^{3} t_{3} & a(18,13)=-\bar{D}_{3} s_{3}{ }^{3} e_{3} & a(18,14)=\bar{D}_{3} s_{3}{ }^{3} e_{30}
\end{array}
$$

19. $i=19$

$$
\begin{array}{llll}
a(19,6)=\bar{D}_{2} s_{2}^{3} c_{5} & a(19,7)=-\bar{D}_{2} s_{2}^{3} t_{5} & a(19,8)=-\bar{D}_{2} s_{2}{ }^{3} e_{5} & a(19,9)=\bar{D}_{2} s_{2}{ }^{3} e_{50} \\
a(19,11)=\bar{D}_{3} s_{3}{ }^{3} c_{7} & a(19,12)=-\bar{D}_{3} s_{3}{ }^{3} t_{7} & a(19,13)=-\bar{D}_{3} s_{3}{ }^{3} e_{7} & a(19,14)=\bar{D}_{3} s_{3} e_{70} \\
a(19,16)=-\bar{D}_{1} s_{1}{ }^{3} c_{6} & a(19,17)=\bar{D}_{1} s_{1}{ }^{3} t_{6} & a(19,18)=\bar{D}_{1} s_{1}{ }^{3} e_{6} & a(19,19)=-\bar{D}_{1} s_{1}{ }^{3} e_{60}
\end{array}
$$


20. $i=20$

$$
\begin{array}{llll}
a(20,1)=\bar{D}_{1} s_{1}^{2} t_{1} & a(20,2)=\bar{D}_{1} s_{1}^{2} c_{1} & a(20,3)=-\bar{D}_{1} s_{1}{ }^{2} e_{1} & a(20,4)=-\bar{D}_{1} s_{1}{ }^{2} e_{10} \\
a(20,6)=-\bar{D}_{2} s_{2}^{2} t_{2} & a(20,7)=-\bar{D}_{2} s_{2}^{2} c_{2} & a(20,8)=\bar{D}_{2} s_{2}^{2} e_{2} & a(20,9)=\bar{D}_{2} s_{2}^{2} e_{20} \\
a(20,11)=-\bar{D}_{3} s_{3}^{2} t_{3} & a(20,12)=-\bar{D}_{3} s_{3}{ }^{2} c_{3} & a\left(20,13=\bar{D}_{3} s_{3}{ }^{2} e_{3}\right. & a(20,14)=\bar{D}_{3} s_{3}{ }^{2} e_{30} \\
a(20,21)=\frac{B_{2}}{A_{2}}-\frac{B_{3}}{A_{3}}-\bar{z}_{2}+\bar{z}_{3} & &
\end{array}
$$

21. $i=21$

$$
\begin{array}{llll}
a(21,6)=-\bar{D}_{2} s_{2}^{2} t_{5} & a(21,7)=-\bar{D}_{2} s_{2}{ }^{2} c_{5} & a(21,8)=\bar{D}_{2} s_{2}{ }^{2} e_{5} & a(21,9)=\bar{D}_{2} s_{2}{ }^{2} e_{50} \\
a(21,11)=-\bar{D}_{3} s_{3}{ }^{2} t_{7} & a(21,12)=-\bar{D}_{3} s_{3}{ }^{2} c_{7} & a(21,13)=\bar{D}_{3} s_{3}{ }^{2} e_{7} & a(21,14)=\bar{D}_{3} s_{3}{ }^{2} e_{70} \\
a(21,16)=\bar{D}_{1} s_{1}{ }^{2} t_{6} & a(21,17)=\bar{D}_{1} s_{1}{ }^{2} c_{6} & a(21,18)=-\bar{D}_{1} s_{1}{ }^{2} e_{6} & a(21,19)=-\bar{D}_{1} s_{1}{ }^{2} e_{60} \\
a(21,21)=a(20,21) & & &
\end{array}
$$

In the above equations,

In addition,

$$
\bar{B}_{n}=\frac{B_{n} s_{n}}{A_{n}} \quad \bar{D}_{n}=D_{n}-\frac{B_{n}^{2}}{A_{n}} \quad B_{m n}=\left(\frac{B_{n}}{A_{n}}-z_{m}\right) s_{n}
$$

$$
\begin{array}{ll}
c_{r}=\cos s_{k} l_{q} & t_{r}=\sin s_{k} l_{q} \\
e_{r}=e^{s_{k} l_{q}} & e_{r 0}=e^{-s_{k_{q}}{ }^{2}}
\end{array}
$$

A correspondence between subscripts $r, \mathrm{k}$ and $\mathrm{q}$ is established in the following Table

\begin{tabular}{|c|c|c|c|c|c|c|c|}
\hline $\mathrm{r}$ & 1 & 2 & 3 & 4 & 5 & 6 & 7 \\
\hline $\mathrm{k}$ & 1 & 2 & 3 & 1 & 2 & 1 & 3 \\
\hline $\mathrm{q}$ & 1 & 1 & 1 & $\mathrm{l}_{\mathrm{q}}=\mathrm{L}$ & 2 & 2 & 2 \\
\hline
\end{tabular}

B. Vector $\left\{\mathbf{f}_{\mathbf{j}}\right\}$

Elements that are not listed are equal to zero.

$\mathrm{f}_{1}=\mathrm{f}_{4}=-\mathrm{F}_{1}$

$f_{8}=-f_{14}=F_{2}-F_{1}$

$f_{9}=-f_{15}=F_{3}-1 F_{1}$

II. Cantilever beam clamped at the left end

The second and the fourth lines of the matrix $\left[\mathrm{a}_{\mathrm{ij}}\right]$ are changed as follows:

$i=2$

$a(2,1)=a(2,3)=-a(2,4)=1$ 
$i=4$

$$
\begin{aligned}
& f_{2}=f_{5}=-\frac{P_{1}}{A_{1}} B_{1} \bar{E}_{z} \\
& f_{6}=\left(\frac{P_{1}}{A_{1}}-\frac{P_{2}}{A_{2}}\right) \bar{E}_{z} l_{1} \\
& f_{7}=\left(\frac{P_{1}}{A_{1}}-\frac{P_{3}}{A_{3}}\right) \bar{E}_{z} I_{1} \\
& f_{12}=\left(\frac{P_{1}}{A_{1}}-\frac{P_{2}}{A_{2}}\right) \bar{E}_{z} I_{2} \\
& f_{13}=\left(\frac{P_{1}}{A_{1}}-\frac{P_{3}}{A_{3}}\right) \bar{E}_{z} l_{2} \\
& f_{20}=f_{21}=\left(\frac{P_{2}}{A_{2}} B_{2}+\frac{P_{3}}{A_{3}} B_{3}-\frac{P_{1}}{A_{1}} B_{1}\right) \bar{E}_{z}
\end{aligned}
$$

$a(4,16)=-\bar{D}_{1} s_{1}^{3} c_{4}$

$$
\begin{aligned}
& a(4,17)=\bar{D}_{1} s_{1}^{3} t_{4} \\
& a(4,19)=-\bar{D}_{1} s_{1}^{3} e_{40}
\end{aligned}
$$

The element $\mathrm{f}_{4}$ of the vector $\left\{\mathrm{f}_{\mathrm{j}}\right\}$ is equal to zero, contrary to the case of a simply supported beam. 
TABLE I-MATERIAL PROPERTIES

[In material coordinates]

\begin{tabular}{|l|c|c|}
\hline \multicolumn{1}{|c|}{ Property } & T300934 & $\begin{array}{c}\text { PZT-5A } \\
\text { (Morgan Matroc, } \\
\text { (ref. 35)) }\end{array}$ \\
\hline $\mathrm{E}^{\mathrm{E}}{ }_{11}(\mathrm{GPa})$ & 150 & 69 \\
$\mathrm{v}_{1} 0.275$ & 0.275 & 0.31 \\
$\mathrm{E}^{\mathrm{E}}{ }_{22}(\mathrm{GPa})$ & 7.3 & 69 \\
$\mathrm{G}^{\mathrm{E}_{66}(\mathrm{GPa})}$ & 3.2 & 26.3 \\
$\mathrm{~d}_{31}(\mathrm{~m} / \mathrm{V})$ & 0 & $-171 \quad 10^{-9}$ \\
$\varepsilon^{\mathrm{s}}{ }_{33}(\mathrm{farad} / \mathrm{m})$ & 0 & $15.045 \quad 10^{-9}$ \\
$\rho\left(\mathrm{kg} / \mathrm{m}^{3}\right) 14957700$ & 1495 & 7700 \\
Ply Thickness(mm) & 0.2544 & 0.254 \\
\hline
\end{tabular}
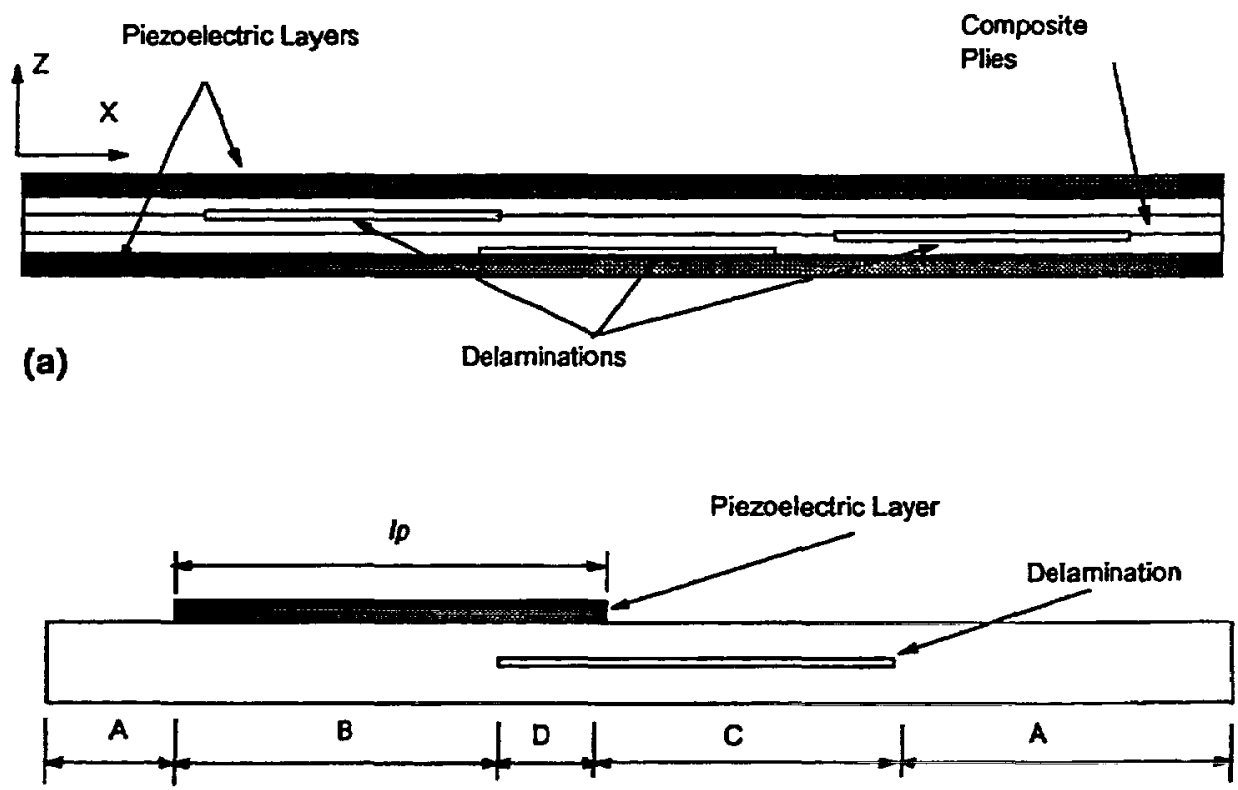

(b)

Figure 1.-Delaminated sensory beam. (a) Typical configuration; (b) Typical beam segments. 


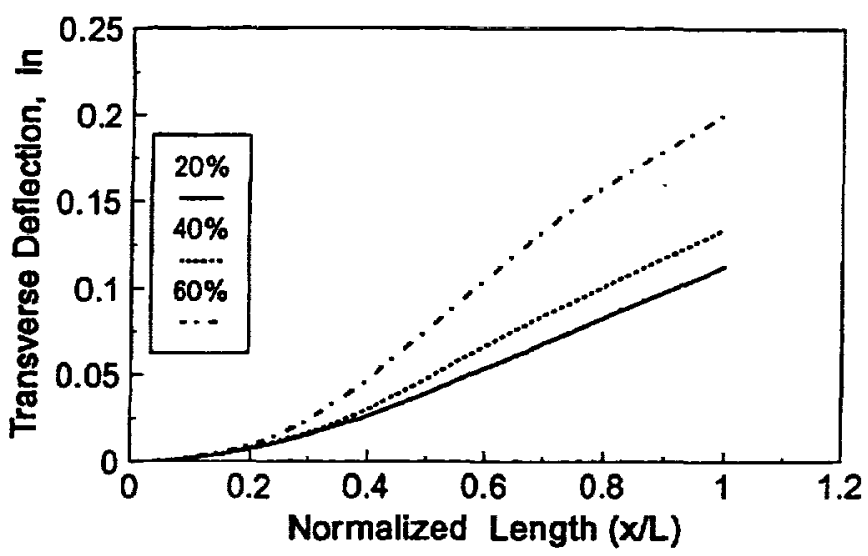

Figure 2.-Effect of delamination length on the dynamic displacement of a cantilever beam. Centrally located delamination.

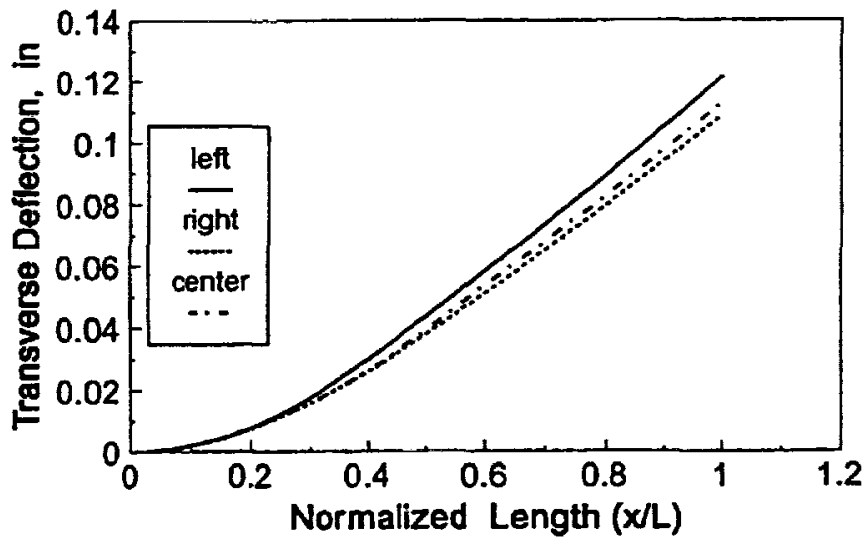

Figure 4.-Effect of the axial location of a delamination on the dynamic displacement. Delamination length $=20 \%$. Coordinate of delamination center is $x_{\alpha} J L$ Left: $x_{\alpha} J L=0.3$; Right: $x_{C} / L=0.7$; Center: $x_{C} / L=0.5$.

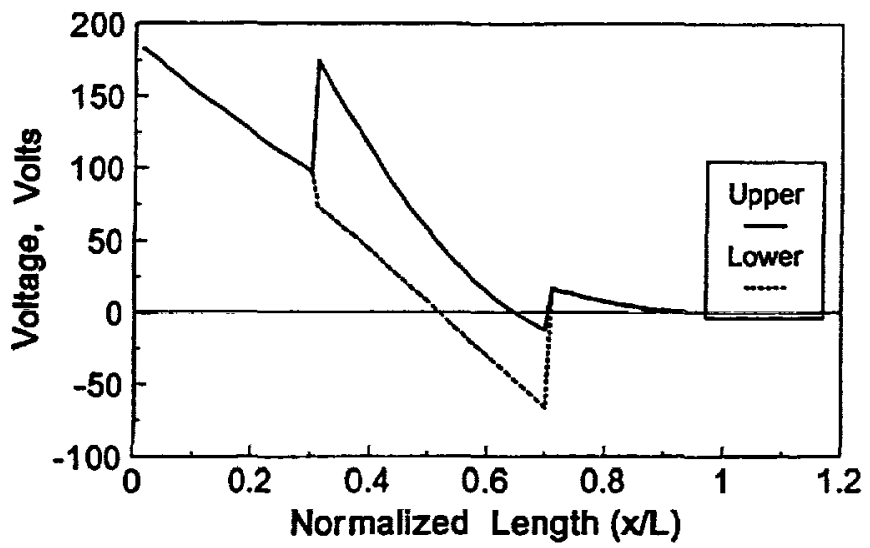

Figure 6.-Detection of a centrally located delamination in a cantilever beam. Delamination length $=40 \%$.

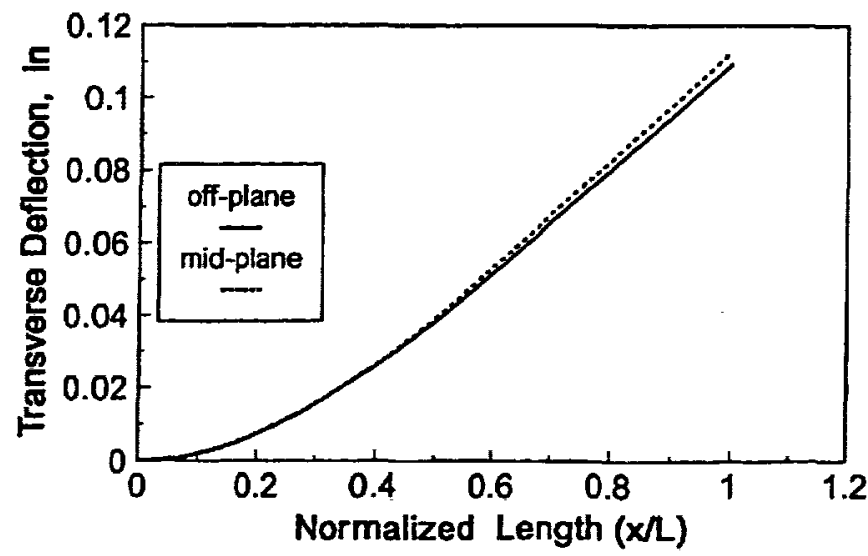

Figure 3.-Effect of through-the-thickness location of a delamination on the dynamic displacement. Delamination length $=20 \%$; lamination: $\left[\mathrm{p} /(0 / 90)_{2} / 90 / 0 / / 90 / 0 / p\right]$.

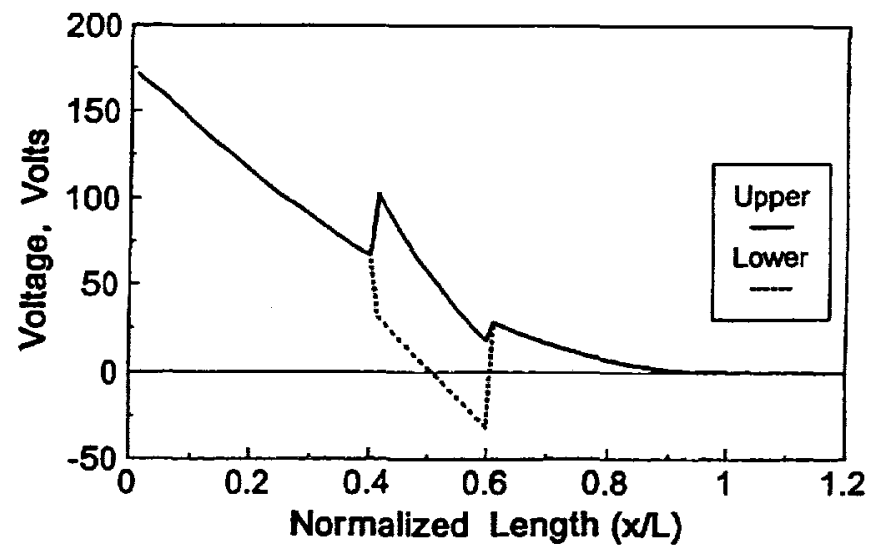

Figure 5.-Detection of a centrally located delamination in a cantilever beam. Delamination length $=20 \%$.

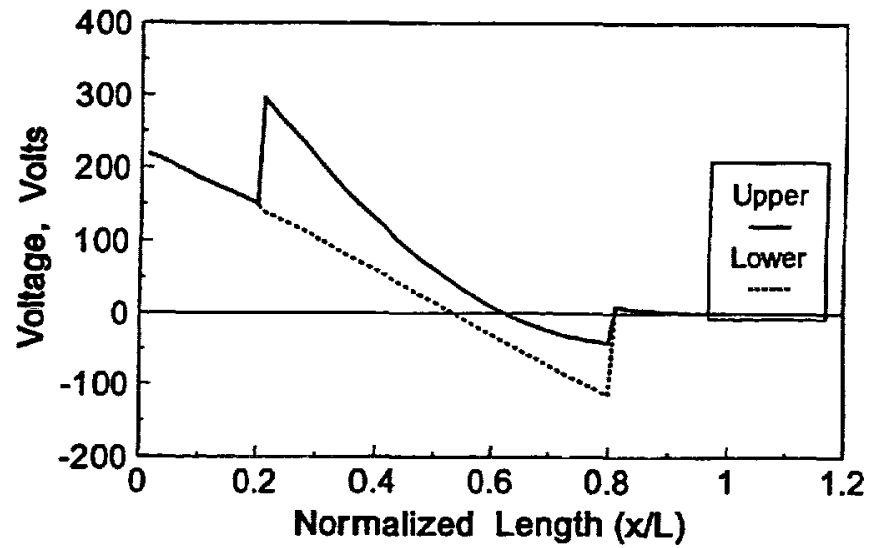

Figure 7.-Detection of a centrally located delamination in a cantilever beam. Delamination length $=60 \%$. 


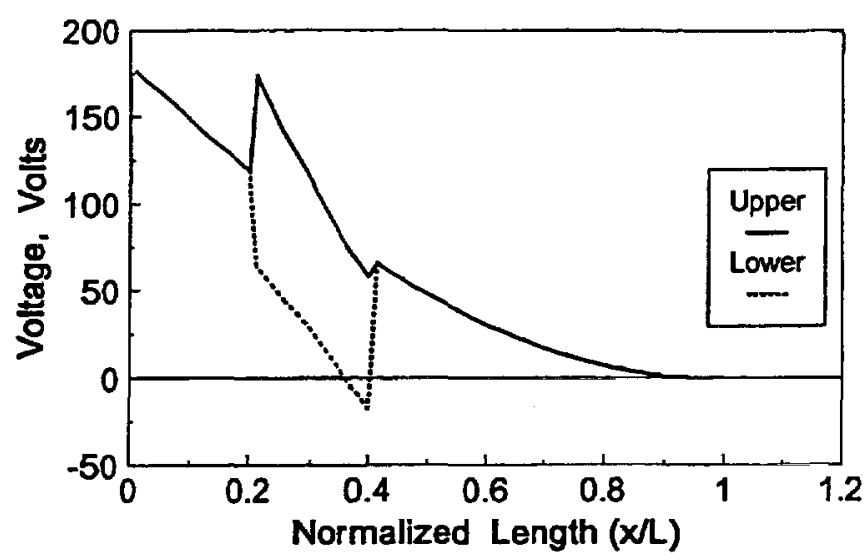

Figure 8.-Detection of an axially shifted delamination in a cantilever beam. Delamination length $=20 \%$. Delamination center is located at $30 \%$ span from the clamped end.

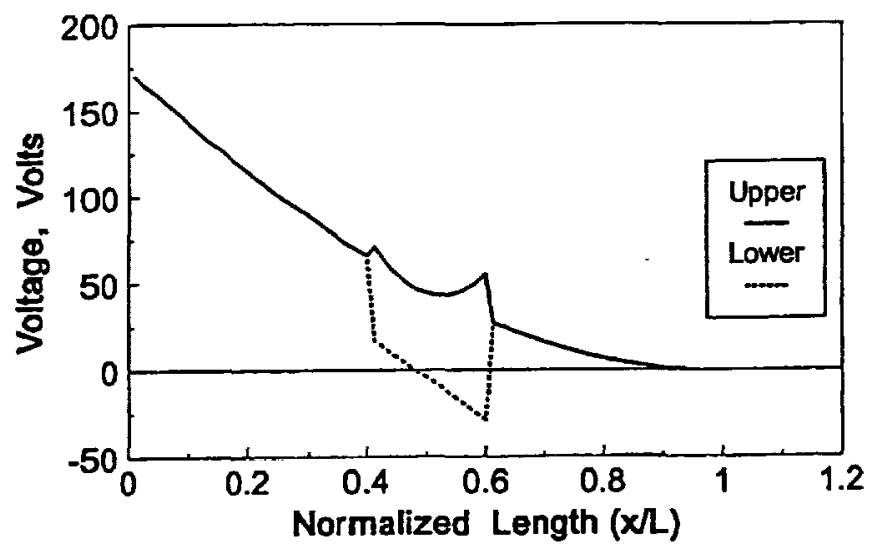

Figure 10.-Detection of a delamination located near the top surface of a cantilever beam. Delamination length is $20 \%$; off-plane delamination: $\left[\mathrm{p} /(0 / 90)_{2} / 90 / 0 / / 90 / 0 / \mathrm{p}\right]$.

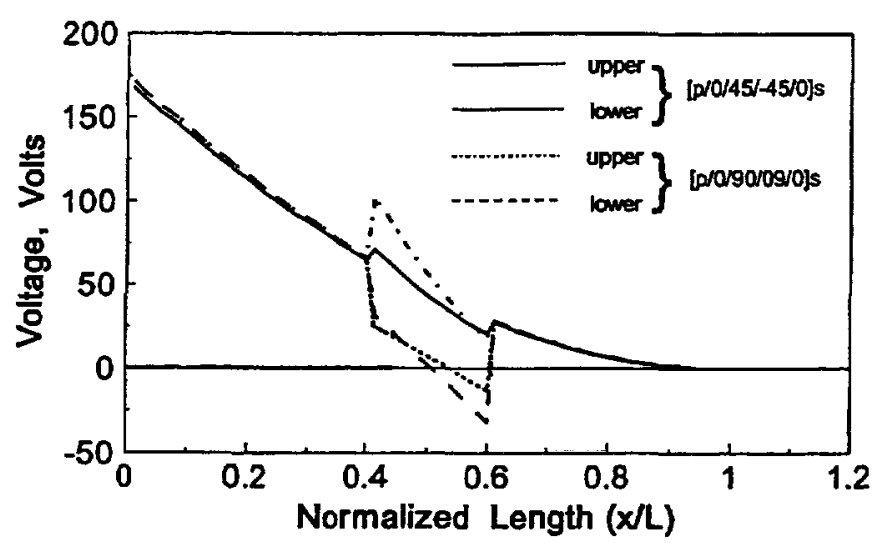

Figure 12.-Effect of laminate configuration on delamination detection. Laminate configurations: $[p / 0 / 45 /-45 / 0]_{s}$ and $[\mathrm{p} / 0 / 90 / 0 / 90]_{\mathrm{s}} .20 \%$ delamination length centrally located at mid-plane.

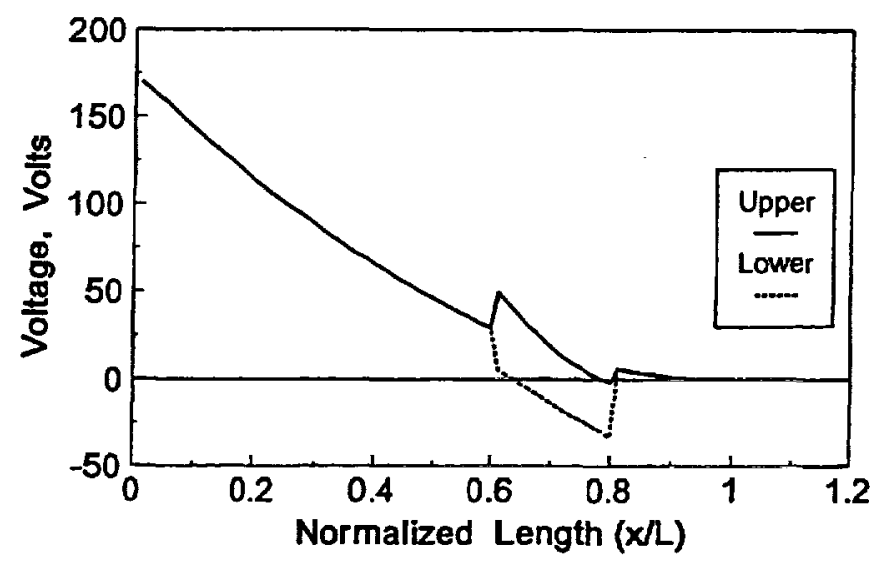

Figure 9.-Detection of an asymmetric delamination in a cantilever beam. Delamination length $=20 \%$. Delamination center is located at $70 \%$ span from the clamped end.

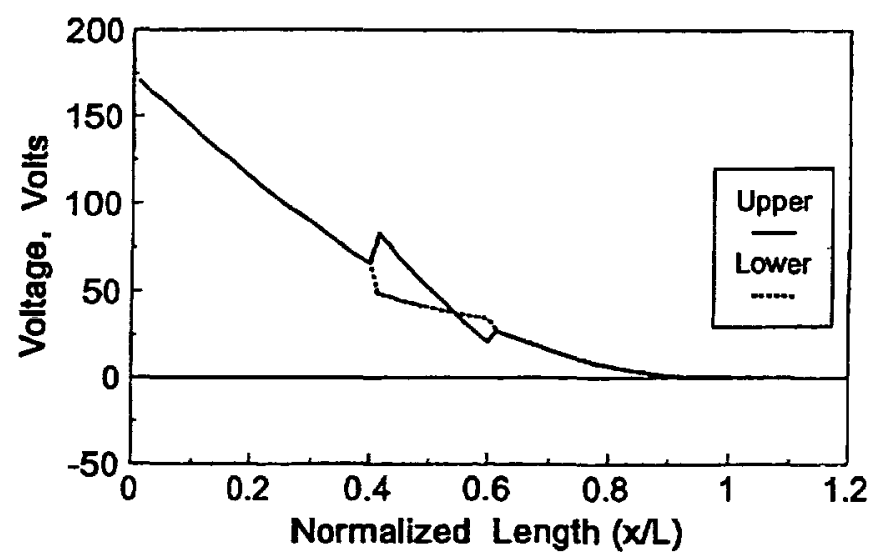

Figure 11.-Detection of a delamination located near the bottom surface of a cantilever beam. Delamination length is $20 \%$; off-plane delamination: [p/0/90//0/90//90/0) $/ 2$ p].

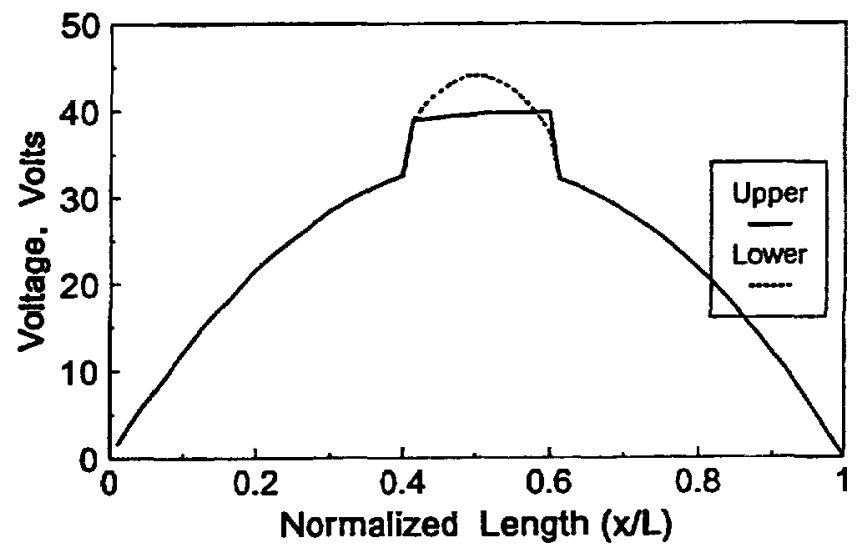

Figure 13.-Effect of simply supporting conditions on delamination detection. Surface of a cantilever beam. [p/0/90/0/90], beam with $20 \%$ delamination length centrally located at mid-plane. 


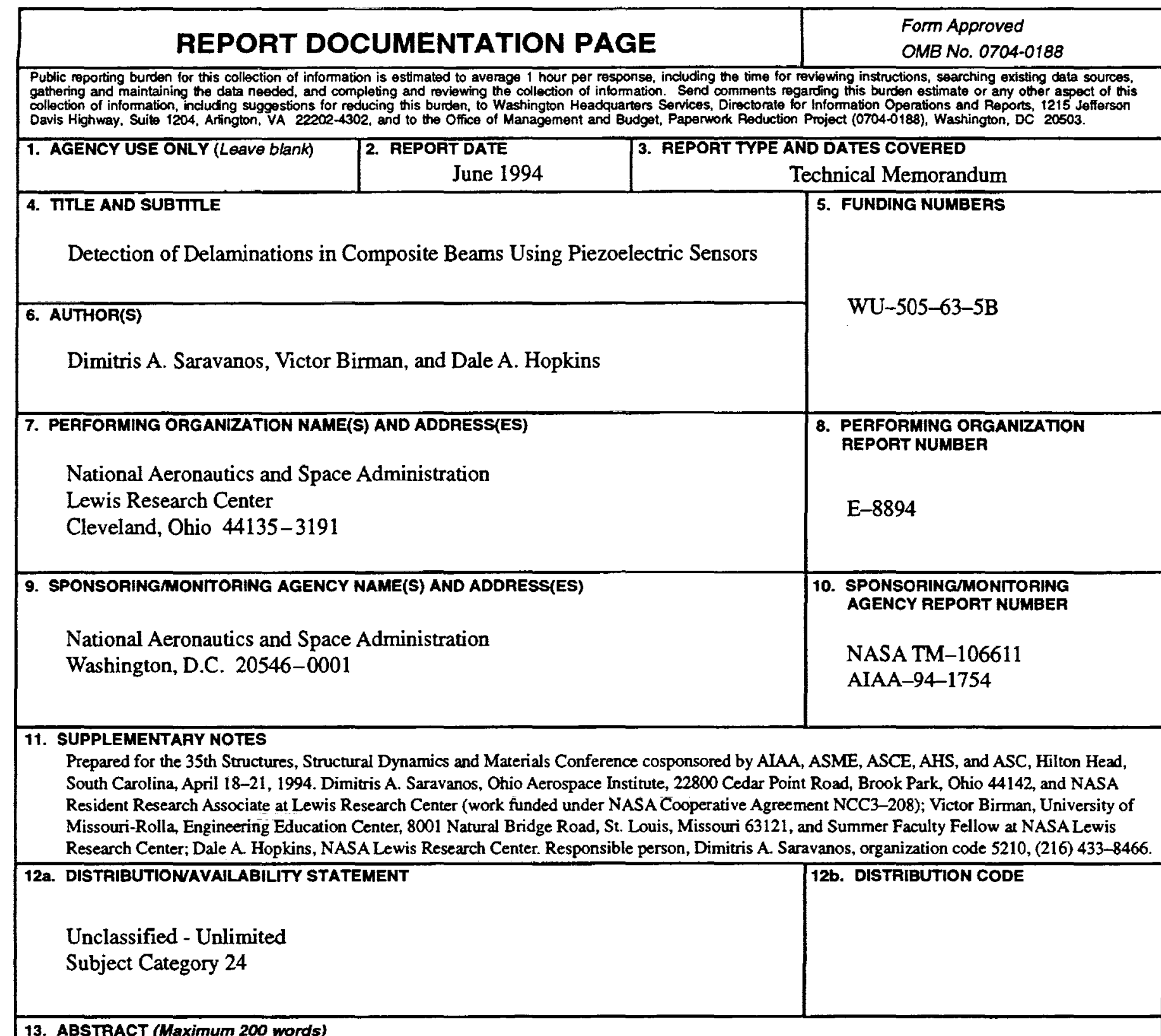

This paper investigates the feasibility of a proposed technique for detecting delaminations using piezoelectric layers or patches embedded or bonded to a composite structure. Variations in the voltage generated in the piezoelectric layers indicates the presence and location of delamination, when the structure is excited either externally or via piezoelectric actuators. The theoretical foundations of a method for predicting the dynamic response of delaminated composite beams with piezoelectric layers are described. The governing equations are presented for the case of external vibroacoustic excitation, as well as, for the case of locally induced vibrations by some of the embedded piezoelectric elements. An exact solution is developed within the limits of linear laminate theory. Applications illustrate the feasibility of delamination detection in cantilever beams. The results illustrate that the proposed technique may provide accurate detection of the presence, size and location of a delamination.

\begin{tabular}{|c|c|c|c|}
\hline \multicolumn{3}{|l|}{ 14. SUBJECT TERMS } & $\begin{array}{c}\text { 15. NUMBER OF PAGES } \\
21\end{array}$ \\
\hline \multicolumn{3}{|c|}{$\begin{array}{l}\text { Composites; Beams; Sensory; Smart; Piezoelectric; Delaminating; Health monitoring; } \\
\text { NDE; Dynamic response }\end{array}$} & $\begin{array}{l}\text { 16. PRICE CODE } \\
\mathrm{A} 03\end{array}$ \\
\hline $\begin{array}{l}\text { 17. SECURITY CLASSIFICATION } \\
\text { OF REPORT } \\
\text { Unclassified }\end{array}$ & $\begin{array}{l}\text { 18. SECURITY CLASSIFICATION } \\
\text { OF THIS PAGE } \\
\text { Unclassified }\end{array}$ & $\begin{array}{l}\text { 19. SECURITY CLASSIFICATION } \\
\text { OF ABSTRACT } \\
\text { Unclassified }\end{array}$ & 20. LIMITATION OF ABSTRACT \\
\hline
\end{tabular}

